\title{
LA PROTECCIÓN DEL TERRITORIO, EL DERECHO AL MEDIO AMBIENTE Y A LA ALIMENTACIÓN, CON REFERENCIA AL CASO DE LOS PUEBLOS ORIGINARIOS “NAHUAS" DE "MALACACHTEPEC" EN MÉXICO, EN CONTEXTO DE LA EPIDEMIA COVID-19.
}

\section{THE PROTECTION OF THE TERRITORY, THE RIGHT TO THE ENVIRONMENT AND TO FOOD WITH REFERENCE TO CASE OF THE "NAHUAS" ORIGINAL PEOPLES OF "MALACACHTEPEC" FROM MEXICO, IN THE CONTEXT OF THE EPIDEMIC CAUSED BY COVID-19.}

\author{
CUITLAHUAC LINA RAMOS \\ Organización ESDH-Espacio Derechos - \\ Doctorante en Ciencias Sociales (Relaciones de poder y cultura política) \\ Universidad Autónoma Metropolitana \\ viajerokevuelva@hotmail.com \\ IVAN LINA RAMOS \\ Maestro en estudios mesoamericanos \\ Universidad Nacional Autónoma de México \\ ivan.lina@hotmail.com
}

Fecha de recepción: 16 de octubre de 2020 / Fecha de aceptación: 27 de noviembre de 2020

RESUMEN: La defensa de la autonomía de los pueblos originarios en Latinoamérica cuenta con una manifestación particular, en la preservación del territorio, entendido a menudo, desde las ontologías relacionales de dichos pueblos como un espacio 
de construcción social material y simbólica. Esta forma particular es la defensa de la soberanía alimentaria bajo el marco del estándar internacional del derecho al medio ambiente y las tensiones ontológico-epistémicas acerca de la noción del territorio. La jurisprudencia de la corte interamericana de derechos humanos proporciona un piso de discusión sobre el sentido de territorio, a partir de esas ontologías, para descubrir la forma en que se relaciona con la noción de medioambiente y la importancia de estos factores en la preservación de la existencia comunitaria de los pueblos, con referencia especial al pueblo nahua de malacachtepec momoxco en la ciudad de méxico, que ha mostrado, desde ese marco de comprensión, una resiliencia especial para enfrentar le epidemia de la Covid-19.

RESUM: La defensa de l'autonomia dels pobles originaris a Llatinoamèrica compta amb una manifestació particular, en la preservació del territori, entès sovint des de les ontologies relacionals d'aquests pobles com un espai de construcció social material i simbòlica. Aquesta forma particular és la defensa de la sobirania alimentària sota el marc de l'estàndard internacional del dret al medi ambienti les tensions ontològic-epistèmiques sobre la noció de territori. La jurisprudència de la cort interamericana de drets humans proporciona un marc de discussió sobre el sentit de territori, a partir d'aquestes ontologies, per descobrir la forma en què es relaciona amb la noció de medi ambient i la importància d'aquests factors en la preservació de la existència comunitària dels pobles, amb referència especial a poble nahua de Malacachtepec Momoxco a la ciutat de Mèxic, que ha mostrat, des d'aquest marc de comprensió, una resiliència especial per enfrontar li epidèmia de la Covid-19.

ABSTRACT: The defense of the autonomy of indigenous peoples in Latin America has a particular manifestation, in the preservation of the territory, often understood, from the relational ontologies of these peoples, as a space for material and symbolic social construction. This particular form is the defense of food sovereignty under the framework of the international standard of the right to the environment and the ontological-epistemic tensions about the notion of territory. The jurisprudence of the inter-american Court of Human Rights provides a floor for discussion on the meaning 
of territory, based on these ontologies, to discover how it is related to the notion of the environment and the importance of these factors in the preservation of the community existence of the peoples, with special reference to the nahua people of malacachtepec momoxco in mexico city, which has shown, from this framework of understanding, a special resilience to face the covid-19 epidemic.

PALABRAS CLAVE: Territorio - Corte interamericana de derechos humanos Pueblos indígenas - Medio ambiente - Soberanía alimentaria.

PARAULES CLAU: Territori - Cort Interamericana de Drets Humans - Pobles indígenes - Medi ambient - Sobirania alimentària

KEY WORDS: Territory - Jurisprudence of the Inter-american Court of Human Rights- Indigenous peoples - Environment - Food sovereignty.

Sumario: I. Introducción; II. Aproximación a la noción de territorio de los pueblos originarios a la luz de la jurisprudencia de la corte interamericana de derechos humanos; III. Aproximación a la noción de medio ambiente frente a la idea de territorio de los pueblos originarios; IV. Los pueblos nahuas de Malacachtepec Momoxco (milpa alta) y el covid-19; 1. contexto; 2. preservación del territorio "momoxco", medioambiente e identidad; 3. la importancia de la soberanía alimentaria en contexto de epidemia; V. Conclusión.

\section{INTRODUCCIÓN}

Las luchas autonómicas actuales centradas en la defensa del territorio de los pueblos originarios en México se presentan en un contexto heterogéneo, dadas las condiciones socio-políticas del país en las que la incidencia del crimen organizado es un factor notorio en diversos aspectos de la vida pública del país; la formal inserción de las fuerzas armadas en la función de seguridad pública y el empleo de estas para ejercer violencia hacia los pueblos originarios; la frecuencia con la que se atenta contra las y los activistas defensores del territorio, y la tendencia abrumadora de las prácticas (neo)extractivas de recursos naturales.

Durante el segundo encuentro de defensores de la tierra organizado por el Fondo de Acción Solidaria - FASOL, en el año 2019, en la ciudad de México, mujeres y 
hombres de 23 de las 32 entidades federativas del país, pertenecientes a 67 diferentes luchas territoriales, organizaciones de la sociedad civil y víctimas de despojo, mostraron el pulso de la extensión de las luchas de los pueblos indígenas por la defensa del territorio a lo largo del territorio frente a las agresiones estatales a este, a sus ocupantes y a sus defensores ${ }^{1}$.

El presente estudio aborda uno de los aspectos de la autonomía de los pueblos originarios que, aunque se inserta desde un marco general, en la dimensión política y legal de la autodeterminación por el gobierno propio, frente a la hegemonía del Estado-nación, se deposita en específico en el ejercicio de la autodeterminación territorial como protección de la integridad cultural histórica. De tal suerte que el propósito es colocar el foco de atención, por medio de un análisis general, en las características de una noción particular de territorio, su relación imperfecta con la noción de medioambiente comprendida en el estándar internacional; lo cual es analizado, desde el ámbito de los derechos humanos, sobre la base hermenéutica de la jurisprudencia de la Corte Interamericana de Derechos Humanos (Corte IDH) relativa a los casos de afectaciones territoriales de los pueblos originarios en la región y algunos estándares del Derecho Internacional de los Derechos Humanos.

La importancia de establecer ese marco radica en la comprensión holística del sentido de la defensa del territorio de los pueblos originarios y el alcance que tiene la protección de este, como ejercicio de defensa de la autonomía, en circunstancias contingentes en la sociedad. En ese marco, se abordará la forma en que se presenta el ejercicio del derecho a la soberanía alimentaria, tomando como referencia el breve estudio de caso de los pueblos nahuas de Malacachtepec Momoxco o Milpa Alta que habitan en un sector rural del sur de la ciudad de México, en el que se advierten características sumamente especiales de constitución territorial en un entorno citadino, de identidad histórica y práctica agrícola, que muestran una forma particular de preservación de lo que en occidente llamamos medioambiente, por un

1 Fondo Acción Solidaria A.C. (FASOL), Relatoría del II Encuentro de defensoras y defensores del territorio. Ciudad de México, 21-23 de noviembre de 2019 [archivo electrónico]. 
lado, y otra forma especial, única, de respuesta de los pueblos nahuas al contexto de la epidemia provocada por la propagación de la COVID-19.

Previamente, juzgamos conveniente aclarar la noción de territorio adoptada en el presente estudio, con la finalidad de sintonizar la comprensión de los alcances que tiene la acción de protección de los territorios, el sentido occidental de medio ambiente y la importancia de la soberanía alimentaria, intentando para ello recurrir a las epistemologías de los pueblos originarios y a las cosmovisiones de estos, siempre en el marco del quehacer jurisprudencial interamericano.

La conceptualización de territorio abordada, facilitaría la comprensión de la relación existente, primero, entre unidades étnicas o pueblos originarios y lo que entendemos como medioambiente; después, ayudaría a intuir las características del vínculo entre el derecho al medioambiente y el derecho a la alimentación, potencialmente útil para la preservación del territorio de los pueblos originarios en la constitución de la existencia comunal, y en particular como se ha dicho, en el contexto de la epidemia.

Cabe aclarar que la elección acerca del abordaje del tema, a partir de la jurisprudencia de la Corte IDH, no es fortuita. Con la más reciente de las sentencias emitidas acerca de pueblos originarios (Lhaka Honat vs Argentina de 2020), ese tribunal ha dado un giro hermenéutico, con auxilio de una interpretación extensiva del artículo 26 de la Convención Americana sobre Derechos Humanos (CADH) ${ }^{2}$, rompiendo el tabú de la incompetencia para conocer y pronunciarse respecto de la mayoría de los derechos llamados Derechos Económicos Sociales Culturales y Ambientales (DESCA) previstos en el Protocolo Adicional a la Convención Americana sobre Derechos Humanos en materia de Derechos Económicos, Sociales y Culturales "Protocolo de San Salvador".

2 El artículo 26 de la CADH esencialmente prevé la obligación estatal de adoptar medidas, mediante la cooperación internacional, para el logro progresivo y efectivo de los derechos económicos, sociales, sobre educación, ciencia y cultura, contenidas en la Carta de la Organización de los Estados Americanos, reformada por el Protocolo de Buenos Aires. 
Apelando a los principios de interdependencia y progresividad de los derechos humanos, la Corte avanzó hacia una nueva configuración del corpus iuris interamericano relativo a la defensa del territorio de los pueblos originarios en el continente, pues con independencia del análisis relativo al derecho a la propiedad colectiva consagrado en el artículo 21 de la $\mathrm{CADH}$, se orientó a la conformación de un criterio extensivo, aunque aún inacabado, de protección de ese derecho, robustecido por su vínculo con los derechos a la identidad cultural, al medio ambiente, al agua y a la alimentación.

\section{APROXIMACIÓN A LA NOCIÓN DE TERRITORIO DE LOS PUEBLOS ORIGINARIOS A LA LUZ DE LA JURISPRUDENCIA DE LA CORTE INTERAMERICANA DE DERECHOS HUMANOS}

Vista como una acción de alcances múltiples, la defensa del territorio de los pueblos originarios debería ser observada, en un marco general, como un ejercicio sustantivo de la preservación de la autonomía - comprendida normalmente como independencia política y legal interna de los pueblos frente a los estados nacionales ${ }^{3}$ - que en sintonía con la perspectiva desde la que se aborda en presente estudio, representa una condición alcanzada gracias al ejercicio de la libre determinación no solamente política - lato sensu - sino en términos generales, cultural, en la que el territorio, como se verá, en tanto que dimensión espacial hetero-compuesta, representa una ratio común, un orden particular de las ontologías de existencia de los pueblos originarios.

Hasta ahora, la hermenéutica contenida en las sentencias dictadas por la Corte IDH respecto de casos relativos a pueblos originarios, ha servido para delimitar en el mundo jurídico de los estados americanos, con base en un nivel de comprensión

3 Héctor Díaz Polanco sugiere que el concepto de autonomía define un régimen especial que configura un gobierno propio (autogobierno) para ciertas comunidades integrantes, las cuales escogen así autoridades que son parte de la colectividad, ejercen competencias legalmente atribuidas y tienen facultades mínimas para legislar acerca de su vida interna y para la administración de sus asuntos. Héctor Díaz Polanco, Autonomía regional: la libredeterminación de los pueblos indios, Siglo XXI/UNAM. México, 1991. 
aún general y cognitivamente primario, de las cosmovisiones indígenas, el concepto de territorio, entendido grosso modo como un espacio multidimensional, heterogéneo, de lo físico y lo simbólico, y no como una simple circunscripción espacial cartesiana, como se asume desde la ontología política tradicional en occidente.

En ese sentido, esa jurisprudencia ha sido hasta ahora de utilidad para ajustar el estándar liberal del derecho a la propiedad previsto en el artículo 21 de la $\mathrm{CADH}$, normalmente articulado en la dimensión individual y en el marco de los llamados derechos civiles y políticos, dotándolo de una racionalidad ajustada a la dimensión colectiva, aunque deberíamos decir comunitaria o comunal, de los pueblos originarios, cuando se ha tratado de las afectaciones a sus territorios.

Ese abordaje hermenéutico ha mostrado que la valoración del territorio se ha centrado en la ponderación del vínculo con la propiedad colectiva, aunque marginalmente se había sugerido la necesidad de razonar de manera diferente ese tipo de violación ${ }^{4}$. Con la más reciente sentencia de fondo emitida por la Corte IDH, en el caso de los pueblos originarios que conforman la organización denominada Lhaka Honhat en Argentina, emitida el 6 de febrero de 2020, con motivo de violaciones a derechos humanos en contra de comunidades indígenas cometidas por el estado argentino, la hermenéutica jurisprudencial dio un giro hacia los llamados DESCA, afín a los principios de progresividad e interdependencia de los derechos humanos, con la que desde el primero de los casos resueltos en el año 2002, había adoptado especialmente bajo la dimensión del derecho a la propiedad colectiva.

$4 \quad$ Mediante el voto disidente conjunto de los Jueces Antonio Cançado Trindade y M. E. Ventura Robles correspondiente a la sentencia relativa al pueblo originario de la comunidad Yakye Axa, consideraron que: "[...] la identidad cultural es un componente o agregado del propio derecho a la vida lato sensu; así, si se afecta la identidad cultural se afecta inevitablemente el propio derecho a la vida de los miembros de la referida comunidad indígena [...] debió razonarse más a fondo sobre el derecho fundamental a la vida, como lo hizo en relación con el derecho a la propiedad [colectiva]". Corte IDH. Caso de la Comunidad Indígena Yakye Axa vs. Paraguay. Fondo Reparaciones y Costas, sentencia de 17 de junio de 2005. Voto disidente conjunto de los Jueces Antonio Cançado Trindade y M. E. Ventura Robles. 
Esta vez, vinculó la noción de territorio no solamente a la propiedad comunitaria, sino a los DESCA como el medio ambiente, al agua, a la alimentación y a la identidad cultural. No es que la relación entre el territorio de los pueblos originarios y el acceso al medio ambiente, o a la identidad cultural no fuesen contemplados anteriormente por la Corte, pero esta vez ha trascendido la racionalidad del derecho a la propiedad para desarrollar una interpretación más acabada de la violación de esos derechos a partir de las afectaciones al territorio de los pueblos originarios del norte de Argentina.

Sin perjuicio de las prestaciones que ha brindado en el Sistema Interamericano de Derechos Humanos (SIDH) la protección de esa modalidad de propiedad, principalmente en términos de dotar a la propiedad de la tierra ocupada por lo pueblos originarios, de certeza jurídica, la ruta de valoración de los derechos humanos previstos en la CADH a partir de las afectaciones al territorio debería tomar otros cauces para la adopción de una racionalidad mayormente efectiva por estar ajustada a la dimensión ontológico-epistémica de las cosmovisiones de los pueblos originarios.

De manera reiterada los pueblos originarios le han transmitido a la Corte, que la categoría de territorio es formadora del sentido de vida entendida como existencia comunal o colectiva. Sin embargo, como se advierte del tratamiento en el caso Lhaka Honhat vs Argentina ${ }^{5}$, los criterios valorativos de violaciones a derechos humanos de los pueblos originarios que la Corte emitió, la llevaron a relacionar las afectaciones al territorio de los pueblos originarios del norte de Argentina con otros elementos disgregados del orden cultural y ambiental, mas no a una definición orientada hacia el sentido ontológico de existencia de dichos pueblos que pudiese, por ejemplo, dotar al artículo 4 de la CADH correspondiente al derecho a la vida interpretado en sentido comunitario o colectivo.

La nueva ruta jurisprudencial que ha trascendido el derecho a la propiedad comunitaria tampoco es improductiva para los pueblos originarios en términos de

$5 \quad$ Corte IDH. Caso comunidades indígenas miembros de la asociación Lhaka Honhat (nuestra tierra) vs. Argentina. Fondo, Reparaciones y Costas, sentencia de 6 de febrero de 2020. 
defensa de sus territorios; sin duda les ha brindado hasta ahora prestaciones a ese interés en el entorno regional interamericano. Sin embargo, representa solamente un nivel primario del desarrollo hermenéutico jurisdiccional interamericano que en nuestro concepto, exige una comprensión diversa, mucho más profunda y desarrollada sobre la base de las ontologías y epistemologías de los pueblos originarios, traducidas en la noción de mundo-existencia, en un nivel cognitivo más profundo sobre la condición estructural comunitaria vinculada a la preservación de la vida comunal o colectiva, entendida como existencia material y simbólica de los pueblos originarios, y no bajo la noción simple de subsistencia o de proyección de vida que ha adoptado a menudo la Corte.

La forma de comprender al mundo, la vida, el territorio, de los pueblos originarios en el entorno interamericano de derechos humanos, se separa de la dicotomía disruptiva de las ontologías binarias o duales occidentales modernas sobre la "tierra" como un elemento de la naturaleza que constituye parte del entorno de las sociedades humanas, que parece asumirse normalmente como un factor exógeno respecto de la constitución social de los grupos humanos. Lo que decimos es que la categoría de territorio refiere a un espacio "meta-ecosistémico", en el que las unidades étnicas y sus estructuras simbólicas conforman una heterogeneidad que va más allá de la concepción tradicional del ecosistema como entorno, decíamos, visto como dimensión exógena del ser humano.

No es menor importancia la incomprensión desde la ontología occidental de los estados, incluso en cierta medida desde la hermenéutica de la Corte IDH, de la noción del territorio que debería ser asumida como espacio-tiempo vital, de interrelación con el mundo natural que circunda y es parte constitutivo de él6; como un espacio material y simbólico, biofísico y epistémico, que contiene procesos de apropiación socio-cultural de la naturaleza y los ecosistemas de cada pueblo desde

6 Arturo Escobar, "Territorios de diferencia: la ontología política de los «derechos al territorio»", en Cuadernos de Antropología Social, núm. 41, 2015. 
su propia ontología o visión del mundo ${ }^{7}$. Consideraremos que se ha acusado el intento de integrar conocimientos de los pueblos originarios y conocimientos científicos modernos, provocando "desentendimientos" que conllevan a una "equivocación sin control", una "falla comunicativa" que se da entre aquellos que viven en ontologías o mundo diferentes, no porque vivan en mundos diferentes, sino porque "no se percatan que el otro está en-actuando ( $y$ asumiendo) un mundo diferente" 8 .

A propósito de tales consideraciones, desde una mirada andina ${ }^{9}$ se ha puntualizado que el modelo de diálogo intercultural cuenta con cualidades argumentativas y el uso de conceptos desarrollados desde el mundo moderno occidental, lo que impide la comprensión de los relatos de otras culturas. Para esta visión, la consideración igualitaria de los pueblos originarios no es verificada con la simple dotación de voz a éstos para manifestar su apreciación respecto del objeto del diálogo, sino de la asunción de las expresiones de ellos y de las instituciones que le dan forma a su pensamiento, que deben ser comprendidas por Occidente. Lo contrario a esto es el despliegue de un monólogo cultural.

El alcance de esas "fallas comunicativas", no es ocioso decirlo, juega un papel importante para la dominación epistémica en la relación de poder que los estados nacionales, a través de las instituciones políticas y jurídicas, en principio asumen frente a los pueblos originarios. En la práctica, el despojo de los territorios de los pueblos originarios - entendiéndose por despojo la apropiación violenta o encubierta bajo formas legales de bienes naturales y de bienes de propiedad comunal $^{10}$ - se percibe como una de las tres etapas del control cultural que según Bonfil Batalla las culturas dominantes ejercen en las relaciones interétnicas y que tiene por efecto la dominación cultural. Esa forma de despojo consiste en la

7 Arturo Escobar, Sentipensar con la tierra: nuevas lecturas sobre desarrollo, territorio y diferencia, UNAULA. Medellín, 2015, <http://biblioteca.clacso.edu.ar/Colombia/escposunaula/20170802050253/pdf_460.pdf> ([Última consulta, 03 de octubre de 2020]).

$8 \quad$ Mario Blaser, "La ontología política de un programa de caza sustentable", en Electronic Journal World Anthropologies Network (WAN), núm. 4, 2009.

$9 \quad$ Javier Hernández, "El encuentro entre la filosofía andina y el pensar andino", en UNAY RUNA 9 Revista de Ciencias Sociales, Yachay, Saberese Andino-Amazónicos, 2018, Lima.

$10 \quad$ Adolfo Gilly y Rhina Roux, El tiempo del despojo, Itaca. México, 2015. 
expropiación (aunque diríamos que también eliminación), por parte de la cultura dominante, de los elementos de la cultura dominada ${ }^{11}$.

Una de las numerosas muestras de la incomprensión del sentido de territorio desde las ontologías de los pueblos originarios, en su defecto, del choque paradigmático observado en la jurisprudencia de la Corte IDH acerca de las nociones de territorio y tierra, se encuentra en el caso del pueblo Mayagna o Sumo de la comunidad Awas Tingni, y Miskita de la costa Atlántica o caribeña en Nicaragua, a propósito del discurso de la representación estatal Nicaragüense, que durante el litigio expresó una idea de lo territorial diluida en el concepto de tierra, comprendida como un elemento de la naturaleza cuya propiedad estatal es entregada en títulos a través de un modelo agrario diseñado para personas campesinas, y no para las unidades étnicas con presencia ancestral en los territorios, como es el caso de los pueblos originarios Mayagna y Miskito.

Desde esa visión, claro está, acorde a un régimen de utilidad para el modelo de apropiación de la tierra para la reproducción de un modelo de economía de mercado primada por la acumulación de la riqueza, la tierra es asumida como un simple medio de subsistencia material, lo que llevó al estado a adoptar un criterio basado en una racionalidad de corte cuantitativo, utilitario de la tierra; es decir, a determinar la extensión de la propiedad de esta que debía otorgarse a dichos pueblos, con base en lo que consideraba, debía ser consistente con la necesidad de subsistencia, orientándose así la racionalidad del discurso oficial en un criterio de dotación suficiente para la subsistencia ${ }^{12}$, lejos aún de una valoración propia del sentido de existencia cultural.

Este abordaje de la idea de tierra, ajena a la del territorio, es consistente con el hecho de que el estado Nicaragüense alegara el carácter nómada del pueblo Mayagna, para negarse a asumir su obligación convencional de adoptar las medidas necesarias para concluir la titulación de la propiedad de las tierras a favor de los

11 Guillermo Bonfil Batalla, "Implicaciones éticas del sistema de control cultural”, en León Olivé (comp.), Ética y diversidad cultural, Fondo de Cultura Económica. Colombia, 1997, p. 198.

12 Corte IDH. Caso de la Comunidad Mayagna (Sumo) Awas Tingni vs. Nicaragua. Fondo, reparaciones y costas, sentencia de 31 de agosto de 2001. 
pueblos Mayagna y Miskito. En un ejemplo de violencia simbólica institucional, el estado recurrió al argumento de calificación de los pueblos originarios como "minorías étnicas" y la supuesta falta de evidencias suficientes para acreditar la ancestralidad de las tierras ${ }^{13}$, desconociendo así la historicidad de estos.

Esta misma racionalidad de la tierra-territorio vista como simple delimitación espacial cartesiana, elemento material atemporal y ahistórica, despojado de la condición cultural, es la que explica en cierta medida que, en otro de los casos resueltos por la Corte IDH, esta vez respecto de los pueblos Kaliña y Lokono en Surinam, el estado persistiera en su momento, en reconocer la personalidad jurídica de personas naturales y legales mientras negaba la personalidad colectiva de los pueblos originarios, otorgado, en consecuencia, títulos de propiedad individual a los primeros, negándose ese derecho desde el diseño de la norma jurídica a los pueblos originarios $^{14}$.

Frente a la noción estrictamente material del concepto de territorio mostrada a menudo por los estados latinoamericanos, emergen explicaciones que encuentran una síntesis aceptable en la voz del antropólogo Rodolfo Stavenhagen, entonces perito participante en el desahogo de evidencias en el caso de los pueblos Mayagna y Miskito. Según precisó ante la Corte IDH, la tierra para los pueblos de la región es un espacio geográfico y social, simbólico y religioso, esencial para su autoidentificación. La precisión fue complementada por el perito Race Hale, quien indicó que los antepasados tienen su sede en el territorio, sitios espirituales ${ }^{15}$. Por su parte, el perito abogado Roque de Jesús Roldán, opinó que la existencia y mantenimiento de la tierra depende de mantener la unidad social, reproducir la cultura y supervivencia física y cultural ${ }^{16}$.

Algunas de las expresiones que emanan de otros pueblos originarios dan cuenta de esta aproximación. Habrá que observar, por ejemplo que en México, para el

13 Ibidem.

14 Corte IDH. Caso pueblos Kaliña y Lokono vs. Surinam. Fondo, reparaciones y costas, sentencia de 25 de noviembre de 2015.

15 Corte IDH. "Caso de la Comunidad Mayagna..." cit.

16 Ibidem. 
pensamiento $\mathrm{Na}$ Savi, la tierra, la naturaleza y la sociedad son elementos de un todo simbólico que cohesionan al pueblo y conforman el territorio. ${ }^{17}$

En el ámbito de la jurisprudencia de la Corte IDH, se observó que para los integrantes de pueblos originarios como el Kichwa de Sarayaku en Ecuador o Yakye Axa en Paraguay, el territorio es un meta-ecosistema compuesto por elementos de la naturaleza que constituyen símbolos de vida y conforman el sentido de mundo, al tiempo que dotan de sentido a su existencia comunitaria ${ }^{18}$, para dar forma a una verdad propia, que reúne las características de una noción compartida de territorio.

Las expresiones emanadas de las ontologías de los pueblos originarios, arrojadas en el entorno de la Corte IDH, han sido hasta ahora consistentes con la apreciación teórica que define al territorio como un espacio de apropiación efectiva de la cultura (prácticas ecológicas, agrícolas, económicas, rituales, etc.) y no como un espacio inerte, ajeno a las relaciones que lo constituyen ${ }^{19}$.

Es en este marco en el que el ejercicio del derecho al medio ambiente, al agua, y en particular, a la soberanía alimentaria, dimensiones que no se conciben sin el espacio multidimensional o el territorio cultural en el que se asienta la identidad de los pueblos, se convierten en eslabones finales de una cadena de autonomía territorial que se traduce en defensa de la vida o existencia comunal. Esa racionalidad se desprende, aunque aun incipientemente, de la conjunción de las cosmovisiones de los pueblos originarios en los casos sometidos ante la Corte, que indican la interdependencia del territorio con la vida de las unidades étnicas, en sentido comunitario, o comunal, o colectivo, y la jurisprudencia reciente de la Corte que amplía el espectro de estudio del territorio a los factores de medio ambiente, agua, alimentación e identidad cultural.

17 Jaime García Leyva, Ña na ka'anyo Nuu Yivi: Lo que pensamos en el mundo, <file:///C:/Users/Cuitlahuac\%20Lina/Downloads/54-109-1-SM.pdf> ([Última consulta, 03 de octubre de 2020]).

18 Corte IDH, Caso del pueblo indígena Kichwa de Sarayaku vs. Ecuador. Fondo y Reparaciones, sentencia de del 27 de junio de 2012; Caso de la Comunidad indígena Yakye Axa vs. Paraguay. Fondo, reparaciones y costas, sentencia de 17 de junio de 2005.

19 Escobar, "Sentipensar con la tierra..." cit. 


\section{APROXIMACIÓN A LA NOCIÓN DE MEDIOAMBIENTE FRENTE A LA IDEA DE TERRITORIO DE LOS PUEBLOS ORIGINARIOS}

Desde la perspectiva planteada hasta el momento, la defensa autonómica de los pueblos originarios sería una forma sustantiva de defensa del territorio, lo que ineluctablemente representa a su vez, la defensa de la existencia de los pueblos originarios, primada por el sentido de comunalidad. Y si la existencia o vida de los pueblos originarios centrada en el territorio tiene las características que hasta ahora hemos destacado, es posible que frente a prácticas de despojo de algunos o todos los elementos del territorio, los integrantes de los pueblos puedan seguir existiendo físicamente, pero no más como entidad comunal o comunitaria; es decir, presenciaríamos, y ya lo habremos hecho antes con la extinción de algunas lenguas, la muerte de los pueblos como colectivos, unidades étnicas, en una circunstancia propia de lo que Rodolfo Stavenhagen llamó "etnocidio" o "genocidio cultural"20.

La defensa de lo que denominamos "vida-territorio"21 de los pueblos originarios bajo estas premisas, adquiere mayor complejidad cuando se trata de que la defensa de la vida se ejerza en un contexto particular de agresión a la tierra contenida en el territorio, interpretada como agresión al ecosistema o al medioambiente, como es el caso de la tala ilegal de árboles en los bosques o la sobreexplotación de la tierra, sobre todo en su forma extractivista, y cuando acontecen eventos o fenómenos de riesgo para la salud pública en la que la respuesta gubernamental es insuficiente $u$ omisa, como en el caso del colapso de los sistemas de salud pública causados por las carencias de este frente a las epidemias que pueden llegar a presentar riesgos especiales para las personas pertenecientes a pueblos originarios, a menudo sometidas a condiciones de vulnerabilidad múltiple.

20 Rodolfo Stavenhagen, La cuestión étnica, El Colegio de México. México, 2001.

21 La categoría "vida-territorio" es propuesta como expresión de la cualidad simbiótica que ambos conceptos exhiben, desde nuestra observación de las cosmovisiones de los pueblos originarios acerca de la conformación del sentido de existencia física y simbólica o cultural. 
Por un lado, en el seno de la comunidad de naciones se ha promovido una visión en cierto sentido "desarrollista" propia de las sociedades occidentales modernas, a través de la idea del medioambiente como entorno natural del ser humano, importante para su desarrollo. El principio primero de la Declaración de Rio sobre el Medio Ambiente y el Desarrollo adoptada en la Conferencia de Naciones Unidas sobre Medio Ambiente y Desarrollo, de 1992, exhibe el sentido bajo el cual se advierte desde la comunidad global de estados, al medioambiente, pues coloca a los seres humanos en aquella posición ontológica dualista que escinde a la comunidad humana de la naturaleza. ${ }^{22}$ La naturaleza es entonces asumida como un "entorno" de las sociedades humanas, y los elementos naturales son considerados "recursos", dentro de una visión utilitarista, en la que los seres humanos nos diferenciamos de tales elementos, en una suerte de "contrareferencia" ontológica.

El Convenio 169 de la Organización Internacional del Trabajo, tratado internacional multilateral que ha representado una referencia importante para el reconocimiento y la defensa de los derechos de los pueblos originarios, acusa también inconsistencias propias de la incomprensión inter-ontológica. Desde el discurso proyectado por el Convenio, se observa la "falla comunicativa" entre occidente y los pueblos originarios. Estos últimos son colocados, en la semántica jurídica convencional, bajo la ontología moderna que, aunque crea sentido desde la visión occidental, toma otro cauce hermenéutico cuando enajena a los grupos humanos, en este caso los pueblos originarios, de la constitución de lo que llamamos medioambiente ${ }^{23}$.

Desde el discurso escrito destacado, advertimos una suerte de sobreposición ontológica que no facilita la comprensión del sentido de unidad-identidad de la

22 Convenio sobre pueblos indígenas y tribales, 1989 (Convenio 169 de la OIT). "Principio 1. Los seres humanos constituyen el centro de las preocupaciones relacionadas con el desarrollo sostenible. Tienen derecho a una vida saludable y productiva en armonía con la naturaleza"

23 El Convenio 169 de la OIT expresa lo siguiente: Artículo 4. 1. Deberán adoptarse las medidas especiales que se precisen para salvaguardar las personas [...] las culturas y el medio ambiente de los pueblos interesados [...] Artículo 29. 1. Los pueblos indígenas tienen derecho a la conservación y protección del medio ambiente [...] 
naturaleza-pueblos, y parece enajenarlos de esta. Se aleja del sentido de territorio que hemos mostrado, ignorando que la descripción normativa que da origen al derecho convencional no corresponde del todo a las ontologías relacionales de dichos pueblos, lo que desde un punto de vista epistémico pone bajo cuestionamiento la legitimidad del tratado vis a vis del reconocimiento cultural de los pueblos.

A pesar de ello, la relación epistémica entre la noción de territorio bosquejada en el presente estudio, con la categoría de medioambiente, ha sido intuida, incipientemente, pero al fin expresada en el seno del SIDH. La Relatora Especial de la ONU sobre los Derechos de los Pueblos Indígenas, Victoria Tauli-Corpuz, en calidad de perito, señaló ante la Corte que:

[EI] derecho internacional ambiental y el derecho internacional de los derechos humanos no deberían considerarse como cuerpos de ley separados, sino como interrelacionados y complementarios. En efecto, los Estados Partes del Convenio sobre Diversidad Biológica (CBD) han incorporado el respeto de los derechos y obligaciones internacionales relacionadas en sus decisiones sobre las áreas protegidas en relación con los pueblos indígenas" [...] El CBD y su interpretación autorizada por la Conferencia de las Partes defienden completamente los derechos de los pueblos indígenas en relación con las áreas protegidas $[\ldots]^{24}$

Por su parte, el perito Jeremie Gilbert declaró ante la Corte, con motivo del caso Kaliña y Lokono, y a propósito de los mecanismos de ponderación de derechos en probable conflicto, entre ocupación territorial por parte de los pueblos originarios y el medioambiente, que:

[Respecto del criterio de necesidad], los pueblos indígenas son parte de la protección natural; no hay ninguna necesidad de expulsar a los pueblos indígenas en nombre de la protección de la naturaleza. [...] Respecto de su legitimidad, la protección de la naturaleza es legítima, pero con base en [lo dicho], los pueblos indígenas son parte de la protección de la naturaleza, así

24 Corte IDH. "Caso pueblos Kaliña y Lokono..." cit. 
que no hay ningún objetivo legítimo para la eliminación de estos pueblos que han sido parte de esos recursos [...]". ${ }^{25}$

La Corte IDH, en el mismo caso, se acercó incipientemente a un entendimiento de la noción del territorio de los pueblos originarios y su relación con la protección del medioambiente, argumentando que:

[...] existe una compatibilidad entre las áreas naturales protegidas y el derecho de los pueblos indígenas y tribales en la protección de los recursos naturales sobre sus territorios, destacando que los pueblos indígenas y tribales, por su interrelación con la naturaleza y formas de vida, pueden contribuir de manera relevante en dicha conservación [...]. ${ }^{26}$

[...] los pueblos indígenas, por lo general, pueden desempeñar un rol relevante en la conservación de la naturaleza, dado que ciertos usos tradicionales conllevan prácticas de sustentabilidad y se consideran fundamentales para la eficacia de las estrategias de conservación. Por ello, el respeto de los derechos de los pueblos indígenas, puede redundar positivamente en la conservación del medioambiente. Por lo expuesto, el derecho de estas comunidades y las normas internacionales de medio ambiente deben comprenderse como derechos complementarios y no excluyentes. ${ }^{27}$

Después, con motivo de la sentencia del caso Lhaka Honhat vs Argentina, la Corte IDH puso el foco de atención en el impacto de los problemas ambientales en los pueblos originarios, apreciando la importancia de los recursos naturales para la supervivencia física o material de dichos pueblos:

[...] diversos derechos pueden verse afectados a partir de problemáticas ambientales, y que ello "puede darse con mayor intensidad en determinados grupos en situación de vulnerabilidad", entre los que se encuentran los pueblos indígenas y "las comunidades que dependen, económicamente o para su supervivencia, fundamentalmente de los recursos ambientales, [como] las áreas forestales o los dominios fluviales". Por lo dicho "con base en "la normativa 
internacional de derechos humanos, los Estados están jurídicamente obligados a hacer frente a esas vulnerabilidades, de conformidad con el principio de igualdad y no discriminación. ${ }^{28}$

En otras latitudes del mapa social humano, la noción de medioambiente podría carecer de sentido con la escisión de la persona humana, de los grupos étnicos, de la idea de pertenencia o integración de un conjunto de elementos que conforman el sentido de vida. Cuando se parte de la noción de territorio expuesta en el presente estudio, las ontologías políticas de los pueblos originarios en Latinoamérica revelan un conflicto de entendimiento con el concepto occidental de medioambiente o de ecosistema, inserto en la cosmovisión dicotómica constituida, entre otros, por la presumible dicotomía de sociedad-naturaleza.

Algunas rearticulaciones de defensa del territorio en la segunda mitad del siglo XX, desapegadas de las posiciones ambientalistas del momento, se aproximaron a las ontologías de los pueblos originarios Latinoamericanos, y quizá tomaran de ellas. Como lo apuntó Arturo Escobar, el sentido de lo ambiental se vio rearticulado, en intereses como la conservación de los bosques desde perspectivas territorialesculturales, como fue visto el proceso de defensa del territorio de comunidades negras en Brasil, encausado por la fórmula: "biodiversidad = territorio + cultura, que precisa, no hay conservación sin control del territorio y toda estrategia de conservación tiene que partir de los conocimientos y prácticas culturales de las comunidades". 29

Es por estos motivos que, según lo advertimos, la relación de lo que llamamos "naturaleza", con los pueblos originarios, no ha sido del todo comprendida en los marcos de composición de los estándares sobre protección al medioambiente. Del lado occidental, la defensa medioambiental suele verse como un motivo de búsqueda de armonía entre los seres humanos y su entorno natural; se mira como una condición necesaria para la subsistencia de las sociedades humanas. Del lado de los pueblos originarios en Latinoamérica, la codificación del territorio que hemos

28 Corte IDH. "Caso comunidades indígenas miembros de la asociación Lhaka Honhat..." cit.

29 Escobar, "Sentipensar con la tierra..." cit. 
bosquejado y la protección del llamado entorno natural no revela un interés únicamente fijado en la supervivencia de los pueblos o de sus integrantes, en el sentido material, sino que acarrea la responsabilidad de preservar además la existencia cultural.

Aclaraciones como las formuladas por el perito Jeremie Gilbert acerca del supuesto conflicto de derechos que los estados han llevado a litigio en la Corte IDH, carecerían de relevancia si la norma jurídica y su hermenéutica lograran integrar el espíritu de las cosmovisiones de los pueblos originarios en defensa del territorio, que dictan, como lo ha dicho Francisco López Bárcenas, "fuente de identidad y parte de su ser [...] lugar de origen" ${ }^{30}$, considerando que, contrario a la episteme liberal de la tradición occidental moderna, "más que los territorios pertenezcan a los indígenas, son estos los que forman parte de aquellos" ${ }^{31}$. El caso del pueblo originario Enxet asentado en la comunidad Yakye Axa enfrentado al estado paraguayo, mostró con claridad que la relación de ese pueblo con la tierra no es utilitaria ni dicotómica, sino que forma parte de un modelo de equilibrio natural simbolizado en la expresión "vivir con la naturaleza", a diferencia de la sociedad moderna occidental que vive de la naturaleza ${ }^{32}$.

Si consideramos que los pueblos originaros en Latinoamérica se consideran parte de ella, el planteamiento epistémico del territorio, desde occidente, debería tomar otro cauce. Hablaríamos, como lo hacemos, no de tanto de su papel relevante en la conservación del entorno medioambiental, como lo ha observado la Corte ${ }^{33}$, sino de su propia conservación y de la conservación de todos al mismo tiempo. Su papel hetero-referencial frente a la naturaleza no cobra sentido respecto a una responsabilidad adquirida hacia ella, sino que, de manera auto-referencial, la preservación de esta es la de sus identidades con profunda raíz histórica, como grupos humanos regidos por el paradigma constitutivo comunitario de vida-territorio.

$30 \quad$ Francisco López Bárcenas, Autonomías y derechos indígenas en México, Pez en el árbol. Oaxaca, 2019 (7ª . Edición).

31 Idem.

32 Corte IDH. "Caso de la Comunidad Indígena Yakye Axa..." cit.

33 Corte IDH. "Caso comunidades indígenas miembros de la asociación Lhaka Honhat..." cit. 


\section{LOS PUEBLOS NAHUAS DE "MALACACHTEPEC MOMOXCO" (MILPA ALTA) Y LA COVID-19}

Luego de acercarnos brevemente a las tensiones ontológico-epistémicas en las que participan las categorías de medioambiente y territorio, podemos abordar una dimensión que particularmente revela su importancia en el contexto de la epidemia de la COVID-19, motivo por el cual se ha dado en gran medida la elección del caso de los pueblos nahuas de Malacachtepec en la ciudad de México. Estos pueblos constituyen una entidad social cuyas características propias, tan particulares, contrastan con el entorno urbano del resto de la ciudad y representan un ejemplo de inserción a la metrópolis, sin ser asimilados a su constitución urbana. En ese entorno, el factor socioambiental, la preservación del territorio ejercida como parte de la identidad, proporciona una de esas características especiales, observada como una condición necesaria para el ejercicio de la soberanía alimentaria, como lo veremos adelante.

\section{Contexto}

En el sur de la ciudad de México está ubicada la Alcaldía Milpa Alta, segunda demarcación más grande de la ciudad, aunque es una de las menos pobladas (1.5\% de la población total de la ciudad) ${ }^{34}$, con amplio territorio rural. Dentro de esa demarcación política se asientan los pueblos originarios nahuas, cuya historia colonial muestra hasta ahora que representan un enclave de preservación, en la época (pos)moderna, respecto de los pocos pueblos originarios asentados en lo que hoy es la ciudad de México.

Las comunidades nahuas de Malacachtepec Momoxco asentadas en doce pueblos, han padecido desde principios del siglo $X X$ afectaciones a su territorio, ora por concesión de explotación del bosque, ora por tala ilegal o proyectos de construcción

34 Instituto Nacional de Estadística y Geografía, Encuesta intercensal 2015, $<$ www.inegi.org.mx/programas/intercensal/2015/> ([Última consulta, 13 de octubre de 2020]). 
e infraestructura que implicaban el fraccionamiento de la tierra, lo que desde entonces ha causado conflictos sociales. En 1949 se habría formalizado la explotación indiscriminada de madera del bosque que habría iniciado cerca del año 1928 aún sin concesión, por una empresa de papel. ${ }^{35}$ Todo ese contexto originó un movimiento social de defensa territorial encausado por los pueblos nahuas, desarrollado entre los años de 1974 y 1982, que consiguió detener la explotación del bosque por parte de la compañía maderera y el pretendido fraccionamiento de este por empresas inmobiliarias ${ }^{36}$. No obstante, esa defensa hasta ahora ocupa a dichos pueblos en la lucha por la preservación del bosque afectado principalmente por la tala ilegal en los montes.

A diferencia del resto de las demarcaciones territoriales de la ciudad, en esta no se asientan grandes cadenas comerciales ni se aprecian grandes estructuras urbanas que modifiquen el paisaje tangencialmente, por lo que se puede afirmar que la región se ubica "más allá de la frontera que simboliza actualmente al desarrollo y que, en el sur de la entidad, está representada por las grandes plazas comerciales"37.

Es posible que estas condiciones puedan observarse, en cierta medida, a la luz de un proceso histórico peculiar, dado el hecho de que "la mayor presencia de los españoles y por tanto del mestizaje ocurrió en las zonas más cercanas de comercio con la región lacustre y por las relaciones comerciales establecidas a partir de la madera y del pulque, por lo que [e]l hecho de que la interacción con el orden impuesto por la sociedad colonial no fue tan intensa en los pueblos de Milpa Alta, sugiere la posibilidad de que hayan conservado de mejor forma sus antiguas costumbres y preservado el idioma náhuatp' ${ }^{38}$

35 Mette Wacher, Nahuas de Milpa Alta, CDI. México, 2006.

36 Iván Gómezcésar, "Pueblos invisibles. Los indios en la ciudad de México", en Raquel Gutiérrez y Fabiola Escárzaga (coord.), Movimiento indígena en América Latina: resistencia y proyecto alternativo", vol. II, UAM/UACM/BUAP/UMSA/UPEA/CEAM/Casa Juan Pablos/Gobierno del Distrito Federal. México, 2006, p. 165.

37 Wacher, "Nahuas..." cit.

38 Teresa Losada, La vigencia de la tradición cultural mesoamericana en Milpa Alta, pueblo antiguo de la ciudad de México, <http://www.scielo.org.mx/pdf/rmcps/v47n195/0185-1918-rmcps-47195-195.pdf> ([Última consulta, 13 de octubre de 2020]). 
Otros factores, como el de las condiciones económicas y geográficas de Malacachtepec habrían influido en la constitución histórica de esos pueblos. En la época colonial, "la situación no fuera tan desesperante como la de otros pueblos indígenas, aparentemente debido a que desde la época prehispánica, Malacachtepec era paso obligado del fuerte comercio y de la tributación de los pueblos de la cuenca de México con los de la tierra caliente de los estados de Morelos y Guerrero"39.

La constitución cultural de esos pueblos, nutrida por esas condiciones posiblemente vigentes antes de la invasión española, y durante la época colonial, podrían ser parte de la herencia cultural que se proyecta actualmente en la condición de los pueblos en la actualidad. También, los rasgos de la región bien podrían representar un ejemplo de resistencia cultural de los pueblos originarios contra el avance del paradigma "desarrollista" económico actual.

El contexto de los pueblos nahuas de Malacachtepec Momoxco pone de manifiesto fortalezas de su constitución histórica, aunque también exhiben la repetición, en menor intensidad, del patrón de violaciones a derechos humanos y las agresiones a la autonomía que a su vez obstaculizan el ejercicio de la libre determinación, que ha sido notorio en Latinoamérica. En su historia reciente, los pueblos nahuas enfrentan un desafío importante de defensa del territorio, como se ha dicho, frente a la tala ilegal que tanto el gobierno de la ciudad de México, como el gobierno federal no han logrado o pretendido frenar, incluso en el contexto de la avanzada militarización de la seguridad pública en el país.

Parte de la investigación que dio origen al presente estudio, se centró en el conocimiento directo de ciertas características orográficas, sociales y culturales de algunos pueblos de Malacachtepec Momoxco, además de dos fuentes directas correspondientes a los testimonios de dos personas nahua-hablantes, pertenecientes a la comunidad asentada en uno de los doce pueblos de esa región, denominada Santa Ana Tlacotenco. Dichos testimonios son considerados

$39 \quad$ Idem. 
particularmente importantes en términos epistémicos, dada su naturaleza y la cualidad de las personas que los emitieron a partir de saberes sustentados por su propia historia cultural, desde la cosmovisión nahua de la región.

Se han advertido, a partir de la muestra testimonial, nociones de la categoría de territorio sintonizadas con otras nociones comunes entre varios de los pueblos de Latinoamérica que han acudido a Comisión Interamericana de Derechos Humanos, y finalmente a la Corte IDH, para emprender litigios en el marco regional, internacional, por la defensa del territorio y el reconocimiento o legalización de este. Por ese motivo, la jurisprudencia de la Corte IDH sigue siendo un parámetro de contraste para otros pueblos originarios en Latinoamérica con problemas comunes.

\section{Preservación del territorio "momoxco", medioambiente e identidad}

La naturaleza "es-así", muerta, monótona, vacía pero que colma incómodamente el espacio, desprovista de toda interioridad. Esta es esencialmente una noción de naturaleza que irritaba a Hegel, según lo precisó el filósofo contemporáneo Byung Chun Hal. La montaña no es esplendorosa porque no tiene libertad - considera el filósofo surcoreano interpretando el pensamiento hegeliano. Es el espíritu el que vendrá a salvar al "hombre" de tan impotente naturaleza - siguiendo tal interpretación ${ }^{40}$.

Desde ese enfoque, el monte efectivamente estará muerto, mientras no esté dotado de ese espíritu de la "razón" y el "conocimiento", igual que si se le destruye como resultado de un espíritu que la hace objeto de poder del "hombre", al margen de una comprensión meta-ecosistémica del mundo. La esencia de las ontologías relacionales de los pueblos originarios es tajantemente diversa a la muestra hegeliana, característica de nuestro pensamiento occidental. El tepetl (cerro o montaña en lengua náhuatl) en las civilizaciones mesoamericanas gozaba de cierta heterogeneidad dinámica, de contenido holístico para la concepción de la vida, de 
sentido de lo comunitario y territorial, sobre un ethos apuntalado en la condición relacional de reciprocidad respecto de la naturaleza ${ }^{41}$.

Vemos también que la "montaña", como componente de un territorio (físico y simbólico) tiene un alcance mayor respecto de la relación entre la naturaleza y las sociedades humanas, visible en esa noción de mundo que fundamenta la existencia, por ejemplo, de los pueblos kichwa-lamistas en Perú, quienes invocan a los cuerpos de la naturaleza con el uso de términos de parentesco como Mama Allpa (el suelo), Pachamama (la tierra), Yakumama (las lluvias/agua), similar a la vivencia emotiva de los pueblos mesoamericanos, y como cuerpos espirituales que nutren y mantienen viva a su sociedad ${ }^{42}$.

Algunos de los integrantes de la Corte IDH, desde su naturaleza liberal, han aprendido gracias a su contacto con los pueblos originarios en Latinoamérica, que el cerro es sagrado debido a la presencia en ellos, de los ancestros en vida y enterrados; que además es parte de su historia y es habitado por un hermano, que es un espíritu que vive debajo del cerro. ${ }^{43}$

Apelando a la tradición mesoamericana, se ha dicho en el contexto de Malacachtepec Momoxco, que "los dioses patronos residen en los cerros o bien se transforman en cerros cuando se funda un pueblo. El Teutli es en Milpa Alta, el cerro del dios patrono. El nombre del cerro como vemos aparece frecuentemente en los mitos, lo que nos permite aproximarnos a su profundo significado religioso" 44

En estas concepciones hallamos un sentido profundo emotivo, "familiar" de la relación de los pueblos originarios con los elementos naturales que a nuestros ojos conforman el medioambiente. Este es un sentido de identidad cultural, término que, empleado por la Corte, da cuenta de la dimensión constitutiva del mundo de los pueblos originarios, y se finca sobre una noción de cultura erigida sobre el sentido

41 Iván Lina, "Altepetl. Una organización territorial comunitaria de Mesoamérica”, en Flores Hernández et al (coord.), Mesoamérica. Una Mirada a través del tiempo, Palabra de Clío. México, 2012, p. 108.

42 Fréderique Apffel-Marglin, “¿Espíritus o recursos naturales? Repensando estas categorías”, en "UNAY RUNA 9..." cit.

43 Corte IDH. "Caso de la Comunidad Mayagna..." cit., voto del juez Cançado Trindade.

$44 \quad$ Losada, "La vigencia de la tradición..." cit. 
de los fenómenos sustanciados por la dinámica relacional, en las que el despliegue ambivalente de lo humano, la acción y el discurso, se materializa ${ }^{45}$. Si se considera esta noción, la cultura será asumida como un factor de comunidad que se encuentra en las formas interpersonales a la luz de un paradigma heterogéneo que brinda la idea de vida, de mundo o universo y todas sus manifestaciones.

Se trata pues de una dimensión colectiva, núcleo de formación del individuo perteneciente a un grupo en el que confluyen las expresiones que, a pesar de su diversidad, se ordenan en función de puntos de encuentro de acción y de discurso, generando así la construcción de una identidad basada en los símbolos comunes que dan sentido a la existencia. En particular, en el caso de los comuneros del pueblo de Santa Ana Tlacotenco, hay un sentido de existencia particular que se proyecta en la acción ecológica de preservación del territorio, por tanto del medioambiente, y que más allá de la idea ecosistémica, representaría la preservación de la identidad como pueblo originario.

La representación comunal de Santa Ana Tlacotenco y las brigadas comunales del pueblo se han organizado recientemente con el fin de defender su territorio de la tala clandestina de árboles vivos, así como de la extracción de piedra y otros recursos naturales, que a partir de la pandemia provocada por la propagación del virus COVID-19, se habría incrementado de una forma notable ${ }^{46}$.

No todos los integrantes del pueblo originario de Malacachtepec Momoxco son comuneros, es decir, no todos los integrantes de los pueblos nahuas de esa región defienden el territorio activamente. En este caso, el sentido de comunalidad, más en sintonía con el paradigma comunitario como eje transversal en la noción de existencia común de los pueblos originarios y afrodescendientes en Latinoamérica, se ve en este caso proyectado particularmente sobre una conducta relacional del pueblo con la tierra: el de la defensa activa frente a las afectaciones más directas,

45 John Thompson, Ideología y cultura moderna. Teoría crítica en la era de la comunicación de masas, Universidad Autónoma Metropolitana. México, 2002.

46 Sandra Hernández, "¡Pobladores de Tlacotenco se organizan para defender sus bosques de talamontes!" 23 de junio de 2020, Diario La Jornada, <https://www.jornada.com.mx/ultimas/capital/2020/06/23/pobladores-de-tlacotenco-se-organizanpara-defender-sus-bosques-de-talamontes-1946.html> ([Última consulta, 4 de octubre de 2020]). 
que bien puede representarse como una forma de defensa de la existencia, de carácter comunal del pueblo como unidad étnica.

La noción de territorio, desde el pueblo de Santa Ana Tlacotenco, parte de una concepción holística muy parecida a la caracterización que recuperamos previamente. "El territorio abarca todo, es la cosmovisión, las tradiciones, la lengua 47 . "El territorio es todo, es la cultura, la lengua, la forma de vida, lo comunal"48. El sentido de "propiedad" del territorio parece vincularse a algunos aspectos entre los cuales la identidad del pueblo, que podría mirarse desdoblada en más de una dimensión - pensamos por ejemplo en la relevancia de la preservación de la identidad basada en las prácticas rituales ancestrales o los símbolos que la tierra en concreto contiene, como es el caso de los rituales y ofrendas que hasta ahora siguen practicándose en cuevas del monte, o el hecho de que las toponimias de los parajes en poblado, en el bosque o los campos de cultivo, se crean en función de los sucesos que ahí acontecieron en la historia de esos pueblos o por las características de la tierra ${ }^{49}$, y que de hecho funcionan como referencias de ubicación efectivas por encima de las nomenclaturas oficiales ${ }^{50}$-, particularmente refleja una posición activa de ciertos integrantes del pueblo hacia lo que podemos interpretar como defensa del entorno medioambiental, luego, la función que esa defensa cumple respecto de la preservación de la identidad: "El monte es nuestro y debemos defenderlo [...] ser comunero, es lo que permite que defendamos la tierra" ${ }^{\prime 1}$.

Las luchas históricas por la propiedad de las tierras y la defensa del territorio en Malacachtepec Momoxco, en particular la lucha por la defensa de los bosques, pueden ser consideradas como parte de la identidad de esos pueblos, posiblemente en mayor medida para unos que otros, pero al fin una lucha que lleva como

47 Entrevista semiestructurada realizada a María Luisa Hernández, integrante del pueblo nahua de la comunidad Santa Ana Tlacotenco, Malacachtepec, de fecha 8 de octubre de 2020.

$48 \quad$ Entrevista semiestructurada realizada a Jovany Iglesias López, integrante del pueblo nahua de la comunidad Santa Ana Tlacotenco, Malacachtepec, y jefe de la brigada para cuidar el bosque, de fecha 8 de octubre de 2020.

49 "Entrevista semiestructurada realizada a María Luisa Hernández..." cit.

$50 \quad$ Wacher, "Nahuas..." cit.

51 "Entrevista semiestructurada realizada a Jovany Iglesias López..." cit. 
consecuencia intrínseca la exigencia de reconocimiento de su existencia. La organización política para esa defensa, decimos, parte de su identidad, convierte a estos pueblos en sujetos políticos colectivos o mejor dicho comunitarios en ejercicio de autodeterminación.

\section{La importancia de la soberanía alimentaria en contexto de epidemia}

Se ha respetado en este estudio, el concepto de medioambiente expuesto en los estándares internacionales, naturalmente, desde la jurisprudencia de la Corte IDH, sin dejar de precisar que este no necesariamente es compatible con la noción de territorio presentada en este texto. Con ese entendimiento, diremos que la preservación medioambiental pensada desde dichos estándares tendrá que integrar la concepción de la "vida-territorio", paradigma de existencia de los pueblos originarios. Por lo tanto, advertir que la costumbre alimentaria en el territorio de los pueblos nahuas de Malacachtpec Momoxco representa un eslabón de la práctica autonómica, en específico, que trasciende la noción de medioambiente, y precisa la preservación de la vida no solamente material o física, sino de la existencia comunitaria, simbólica o cultural.

Por otro lado, consideramos que la apropiación y el dominio de la "vida-territorio" como capacidad de agencia comunal y el control social de la tierra, que los pueblos nahuas en Malacachtepec tienen hasta ahora - a menudo, incluso, en un orden meta-legal regido por la posesión histórica, es decir, sin títulos de propiedad oficiales en el caso de las tierras comunales - es la condición de posibilidad para que dichos pueblos controlen la forma de aprovechamiento de la tierra y el territorio para su reproducción física, en términos de lo que se ha dado por llamar seguridad y soberanía alimentarias.

La "soberanía alimentaria"52 es un indicador de utilidad para la comprensión del derecho a la alimentación en el marco de la defensa del territorio de los pueblos

52 El concepto de soberanía alimentaria fue descrito en la Declaración Final del Foro Mundial sobre Soberanía Alimentaria, del 7 de septiembre de 2001, de la Habana, Cuba, el derecho de los pueblos a definir sus propias políticas y estrategias sustentables de producción, distribución y 
originarios en Latinoamérica como forma de defensa sustantiva de la autonomía y el derecho a la libre determinación. Tenemos que considerar en principio, que la categoría de soberanía alimentaria representa la formulación semántica que abre las posibilidades de concebir una forma de protección del territorio por su valor para la subsistencia de los pueblos originarios y el valor cultural para ellos, de los alimentos que la tierra, lato sensu, produce.

A propósito de la función cultural que los alimentos proporcionados por la tierra tienen en los pueblos originarios y la importancia en ello de la protección del territorio, el Relator Especial sobre el Derecho a la Alimentación, de la ONU, ha explicado con lucidez que:

[...] comprender lo que significa el derecho a la alimentación para los pueblos indígenas es mucho más complejo que lo que dimana de un simple análisis de las estadísticas sobre hambre, malnutrición o pobreza. Muchos pueblos indígenas tienen sus propias concepciones particulares de lo que es la alimentación, el hambre y la subsistencia. En general, es difícil separar conceptualmente la relación de los pueblos indígenas con los alimentos, de sus relaciones con la tierra, los recursos, la cultura, los valores y la organización social.

Los alimentos, la obtención y el consumo de alimentos suelen ser una parte importante de la cultura, así como de la organización social, económica y política. Muchos pueblos indígenas entienden el derecho a una alimentación adecuada como un derecho colectivo. Normalmente consideran que las actividades de subsistencia como la caza, la pesca y la recolección son fundamentales no sólo para garantizar su derecho a la alimentación, sino también para nutrir sus culturas, idiomas, vida social e identidad. Con

\footnotetext{
consumo de alimentos que garanticen el derecho a la alimentación para toda la población, con base en la pequeña y mediana producción, respetando sus propias culturas y la diversidad de los modos campesinos, pesqueros e indígenas de producción agropecuaria, de comercialización y de gestión de los espacios rurales, en los cuales la mujer desempeña un papel fundamental. El concepto abarca una serie de principios que esencialmente se centran en la sostenibilidad medioambiental, social y económica que resiste al comercio corporativo, por lo que favorece el comercio transparente de los mercados locales, modelo de gestión de los recursos naturales en los territorios se encuentren bajo el control de quienes producen los alimentos bajo este sistema, promueve el reconocimiento y participación de los pueblos originarios y negros en el modelo y en la defensa de la autonomía necesaria para el modelo, y exige reformas agrarias adecuadas a las características de cada país.
} 
frecuencia, su derecho a la alimentación depende estrechamente del acceso y el control que tengan respecto de sus tierras y otros recursos naturales existentes en sus territorios. ${ }^{53}$

El estándar internacional del derecho a la alimentación destaca la obligación estatal de adoptar políticas dirigidas a los sectores sociales en situaciones de vulnerabilidad. El Comité de Derechos Económicos Sociales y Culturales (Comité DESC) ha considerado que:

[...] el derecho a una alimentación adecuada [...] es indispensable para el disfrute de otros derechos humanos [e] inseparable de la justicia social, pues requiere la adopción de políticas económicas, ambientales y sociales adecuadas, en los planos nacional e internacional, orientadas a la erradicación de la pobreza y al disfrute de todos los derechos humanos por todos ${ }^{54}$.

En particular, una interpretación progresista del organismo quasi-jurisdiccional en el seno de la ONU, destacaría que el respeto a la autodeterminación en el ámbito de la alimentación de los pueblos originarios es una consideración fundamental del cumplimiento de la obligación de adoptar las políticas públicas para la protección del derecho a la alimentación, lo que tendría que implicar naturalmente la protección del entorno medioambiental que hace posibles las condiciones de autosustentabilidad de los pueblos en sus territorios en los que se ejerce un aprovechamiento de los llamados recursos naturales, fuera del modelo de explotación comercial, lo cual refleja de sí parte de su cosmovisión.

Según se ha observado de manera directa, en su plasticidad y desdoblamiento estos pueblos parecen haberse adaptado, y resistido en cierta medida a la inercia moderna del "progreso" visto en la dimensión del avance de la urbanización en la ciudad, por ejemplo, preservando ciertas características del territorio inherentes a su condición comunitaria, como pueblo originario, espacios amplios de actividades agrícolas y forestales, así como la escasa presencia de locales comerciales de gran

53 Relator especial de las Naciones Unidas sobre el derecho a la alimentación. El derecho a la alimentación.

$54 \quad$ Comité DESC, Observación General 12. El derecho a una alimentación adecuada (artículo 11). 
envergadura, formando así una diferenciación importante respecto de las regiones urbanas que integran la ciudad.

Es en este contexto en el que, atendiendo al estándar internacional expuesto, el Gobierno de la Ciudad de México y el de la Alcaldía, han tenido hasta ahora una responsabilidad sustantiva, si no de establecer políticas públicas que garanticen el derecho al territorio de los pueblos nahuas, al menos de abstenerse de adoptar medidas que afecten de manera importante la constitución del territorio y las condiciones que hasta ahora parecen hacer posible su reproducción física y cultural, en términos de acceso a una alimentación sana, propia de su cultura, guiándonos por la opinión expresada por el Relator Especial sobre el Derecho a la Alimentación. Esta protección estatal es relevante para reconocer y respetar el arraigo a la tierra, así como a las costumbres que conforman la vida de los pueblos nahuas de la región que no parten de una simple relación objetiva con los llamados recursos naturales, sino que tienen un trasfondo histórico que se expresa como parte de la identidad de los pueblos, en el sentido que se ha expuesto y cuya preservación se mantiene como un factor primordial su reproducción ${ }^{55}$. Esto explica, por ejemplo, que el motivo más importante para dedicarse a la agricultura en los pueblos nahuas de la región se debe a la tradición heredada en las familias ${ }^{56}$, así como ocurre con la defensa del bosque.

El llamado ecosistema en el territorio momoxco refleja la diversidad de especies animales, por ejemplo, cuyo hábitat es el bosque en el que viven venados, gatos monteses, tuzas, ardillas, ratas de campo, conejo, coyotes, cacomixtles, tlacoaches, gallinas de monte, tortugas de tierra, codornices, armadillos, comadrejas, entro otras especies. Por otro lado, en el monte se encuentran hongos y yerbas diversas como el toronjil, tabaquillo y el pericón. El territorio propicia las condiciones para el cultivo preponderante de nopal (cactus) y del maíz (elote), así como de árboles frutales y hortalizas entre las que se encuentran: manzano, guayabo, limón, ciruelo,

55 Roberto Bonilla, "Urbanización rural y economía agrícola de sobrevivencia en la Delegación Milpa Alta", en la revista Argumentos, núm. 74, 2014.

56 Ibidem. 
chabacano, chile, tomate, jitomate, frijol, haba, calabaza, acelga, espinaca y chícharo, entre otros, al tiempo que brotan de manera silvestre el quelite, los quintoniles, la verdolaga, la flor de calabaza, entre otros. ${ }^{57}$

La biodiversidad en el territorio nahua conforma la base del ecosistema, de su hábitat que, en particular, les brinda las posibilidades de existir en un ambiente que les ofrece las fuentes de alimentación que conforman el modelo de seguridad y soberanía alimentaria para ellos. Es notable el hecho que, además de las posibilidades económicas y de sustento que brinda el cultivo del nopal y su comercialización como dato destacado, alcanza a cubrir cerca del $80 \%$ de la demanda de ese producto en la ciudad de México ${ }^{58}$, el cultivo de las especies de yerbas, frutas y verduras, así como el maíz, se realiza de manera habitual en los núcleos poblacionales de los pueblos para su consumo propio.

Esta forma de autosuficiencia alimentaria, posible gracias a la preservación de los núcleos rurales en el territorio, sea por vía de la que es considerada como propiedad comunal o por la vía del ejido, y a la forma de vida particular basada en la cosmovisión de los pueblos originarios nahuas del Malacachtepec Momoxco, es lo que lleva a aclarar, desde una de las voces del pueblo de Santa Ana Tlacotenco, que: "no necesitamos supermercados, tenemos lo que necesitamos para vivir [...] un alto porcentaje de consumo de maíz es de nuestra propia siembra"59. En la sustentabilidad que hace posible la soberanía alimentaria de los pueblos nahuas momoxcas, también participa un factor definitivo: en la actividad agrícola participan mayoritariamente las familias con su mano de obra ${ }^{60}$.

El valor de esta autosuficiencia es innegable si consideramos que, en razón de un ejercicio comparativo, el pueblo de la comunidad Xakmok Kasék en Paraguay, dada su condición de pueblo nómada, y las diversas violencias estatales que han derivado en el despojo territorial, se ha visto impedido para acceder a la caza, a la recolección y aprovechamiento de los frutos de la tierra. En este caso, el derecho a

57 "Entrevista semiestructurada realizada a Jovany Iglesias López..." cit.

58 Wacher, "Nahuas..." cit.

59 Idem.

60 Bonilla, "Urbanización rural..." cit. 
la alimentación no solamente se vio afectado en el sentido de la protección ambiental del territorio, sino que se agravó con la imposición de una dieta alimentaria limitada, pobre, con deficiencias nutricionales importantes, proporcionada por el gobierno en las llamadas "estancias", campos de marginación y pobreza en los que fueron controlados los integrantes de dicho pueblo, faltando así al cumplimiento de la obligación estatal paraguaya relativa, entre tantas otros rubros, de respetar y proteger el territorio indígena y a garantizar el derecho a la alimentación conforme a los criterios de accesibilidad, disponibilidad y sostenibilidad que conforman el estándar internacional ${ }^{61}$.

Las experiencias comparadas, particularmente a la luz del caso del pueblo nahua de Malacachtepec, muestran que el respeto y la garantía plena estatal de la seguridad y soberanía alimentaria de los pueblos, es indispensable para que estos enfrenten las consecuencias de las pandemias, las hambrunas, la pobreza, y los problemas de salud pública, y que a su vez conciban la defensa del derecho al medioambiente como defensa de la vida material y cultural, frente a actos de explotación desmedida de los llamados recursos naturales, o de otras imposiciones de carácter comercial provenientes de un mercado global, potencialmente aniquilador de las prácticas económicas vinculadas a la producción agrícola de los pueblos nahuas momoxcas y que conforman su propio modelo de soberanía alimentaria.

Por un lado, las y los agricultores de Malacachtepec cultivan principalmente el nopal, aunque no dejan de sembrar el maíz y el frijol. ${ }^{62}$ Por otro lado, a pesar de las dificultades de la comercialización del producto, el nopal sigue contando con una posición importante en el sustento económico y alimentario de los pueblos nahuas de la región, que además participaría en la constitución cultural de los pueblos, tal y como lo expresó un campesino de edad avanzada al manifestar su orgullo de ser "nopalero" y de vivir en Milpa Alta, relatando la forma en que algunos campesinos

61 Corte IDH. Caso de la comunidad indígena Xákmok Kásek vs. Paraguay. Fondo, reparaciones y costas, sentencia de 24 de agosto de 2010.

62 Roberto Bonilla, "Agricultura y tenencia de la tierra en Milpa Alta. Un lugar de identidad" en la revista Argumentos, núm. 61, 2009. 
sí lograron hacerse ricos con el nopal, y enfatizando que «el nopal ya no te hace rico; pero tampoco te mata de hambre, por eso lo seguiremos cultivando»"63.

La importancia que el nopal, el maíz y el resto de los productos de la tierra tienen en los pueblos de Malacachtepec, es, en suma, la de la integración de un componente del territorio que se traduce en la producción de la tierra para la supervivencia, para permitir la subsistencia de dichos pueblos, pero también la reproducción de la unidad cultural, porque la inercia histórica ha provocado que el cultivo de nopal, sea para consumo doméstico o para comercialización en un modelo afín a la soberanía alimentaria, un elemento importante de la identidad cultural nahua momoxca.

Es destacable el hecho de que mientras la agricultura nacional sufría una fuerte crisis en la década de 1980, en Milpa Alta el cultivo del nopal vivía condiciones favorables, lo que hasta ahora, ha impedido que los campesinos de Malacachtepec caigan en la crisis que el resto del campesinado en el país ha tenido ${ }^{64}$, principalmente desde la reforma agraria de los años noventa del siglo pasado, que modificó el estatuto de las tierras agrícolas para introducirlas al mercado de explotación conforme al modelo económico de mercado global. La autonomía alimentaria en el caso de los pueblos nahuas de Malacachtepec tiene una base fuerte, sin duda, en el cultivo del nopal.

El cultivo del nopal, el del maíz y otros productos de la tierra, así como de recolección del bosque, son el sistema que puede dotar a una región como la de Malacachtepec, de fortalezas para enfrentar situaciones de riesgo como la pandemia provocada por la propagación del virus COVID-19, como sorpresivamente se ha observado en esta región. Actualmente se cuenta con datos objetivos que nos han permitido observar la forma en que, desde el contexto histórico territorial mostrado, los pueblos nahuas momoxcas han enfrentado la 
epidemia provocada por la propagación del virus COVID-19 de una forma muy especial, bajo circunstancias destacables, únicas, como a continuación se muestra.

De manera preliminar, es importante destacar que en México es a la fecha el cuarto país con más decesos por COVID-19 en el mundo. ${ }^{65} \mathrm{El}$ impacto de la pandemia entre la población mexicana es particular, pues a diferencia de otros países como España, Italia o China, las afectaciones no se dieron en personas de edad avanzada, sino en aquellas entre los 25 y 65 años. ${ }^{66}$ Además, hay otra particularidad que caracteriza la evolución del virus en México y justifica la pertinencia del análisis hasta aquí expuesto: los decesos causados por e la COVID-19 están estrechamente relacionados con enfermedades derivadas de una alimentación deficiente, basada en productos industrializados con alto contenido en azúcares y grasas.

De acuerdo con los datos del último censo poblacional realizado en México (2015), la población indígena constituye el $10.1 \%$ de la población total ${ }^{67}$. Destacaremos que, de acuerdo con la medición multidimensional de pobreza, los pueblos originarios en México, el $69.5 \%$ se encuentra en situación de pobreza, mientras que el $27.9 \%$ en pobreza extrema ${ }^{68}$. Por otra parte, el aumento de afectaciones por la pandemia se ha acrecentado en dichos pueblos, puesto que en julio de 2020 se registraron 4140 casos positivos de COVID-19 y 719 decesos $^{69}$, mientras que, para septiembre del mismo año, se contaba con un registro de 9179 casos positivos de COVID-19, así como 1334 decesos por esa causa ${ }^{70}$.

65 Centro de Investigación sobre el Coronavirus, Universidad John Hopkins, EE.UU, $<$ https://coronavirus.jhu.edu.> ([Última consulta, 14 de octubre de 2020]).

66 Gobierno de México, <https://coronavirus.gob.mx> ([Última consulta, 14 de octubre de 2020]).

67 Gobierno de <México, https://www.gob.mx/inpi/es/articulos/mujeres-indigenas-datosestadisticos-en-el-mexico-actual?idiom=es> ([Última consulta, 14 de octubre de 2020]).

68 Consejo Nacional de Evaluación de la Política de Desarrollo Social, La pobreza en la población indígena de México, $2008 \quad$ - 2018 , <https://www.coneval.org.mx/Medicion/MP/Documents/Pobreza_Poblacion_indigena_20082018.pdf> ([Última consulta, 12 de octubre de 2020]).

69 Instituto Nacional de los Pueblos Indígenas, <https://twitter.com/inpimx/status/1288271852557787137?s=21> ([Última consulta, 12 de octubre de 2020]).

70 Secretaría de Salud, <https://coronavirus.gob.mx/wp-content/uploads/2020/10/panoramacovid19-poblacion-indigena-240920.pdf> ([Última consulta, 12 de octubre de 2020]). 
Con el fin de comprender de manera precisa el impacto del virus en el pueblo originario nahua de Malacachtepec, empleamos la base de datos abierta de la Secretaría de Salud de México ${ }^{71}$ para realizar un análisis estadístico del área metropolitana de la ciudad de México. Los resultados generales arrojaron que existen tres aspectos vinculados frecuentemente con la mortalidad: el primero es la estrecha relación de los decesos con enfermedades como la diabetes, la hipertensión y la obesidad; el segundo es la solicitud de atención médica a destiempo por parte de los contagiados, así como su ingreso tardío a las instituciones de salud especializadas; y el tercero es la reticencia de un importante sector de la población a acudir de manera pronta a las clínicas, derivado de la desconfianza hacia el sistema de salud mexicano.

Con respecto a las comorbilidades asociadas al alto porcentaje de defunciones, el gobierno mexicano las ha caracterizado desde hace un par de décadas como serios problemas de salud pública, vinculados directamente a una mala alimentación. El alto porcentaje de diabetes y obesidad en México se ha originado por el consumo excesivo durante décadas de azúcares en bebidas carbonatadas y alimentos procesados, así como por la nula regulación gubernamental de éstos tratándose de la distribución dirigida a niños, jóvenes y jóvenes adultos. Según la Organización Mundial de la Salud (OMS), México ocupa el noveno lugar en diabetes a nivel mundial, manteniendo un crecimiento constante que lo podría poner en los primeros lugares la siguiente década. ${ }^{72}$ La hipertensión, que es otra de las enfermedades comunes en México ( 1 de cada 4 personas la padecen), ${ }^{73}$ está muy asociada a las dos enfermedades anteriores y figura como la principal comorbilidad en los casos de COVID-19.

Por otra parte, el segundo elemento recurrente es el ingreso tardío de los enfermos a las instituciones de salud. El análisis arrojó que, en promedio, los pacientes

71 Gobierno de México, <https://www.gob.mx/salud> ([Última consulta, 14 de octubre de 2020]).

72 Organización Mundial de la Salud, Informe mundial sobre la diabetes, 2016.

73 Ismael Campos et al., "Hipertensión arterial en adultos mexicanos: prevalencia, diagnóstico y tipos de tratamientos.", en Salud pública de México, vol. 60, núm. 3, 2018. 
ingresan de 7 a 8 días después de sentir los primeros síntomas. Tomando en cuenta que a partir de los primeros malestares la enfermedad avanza rápidamente y puede llegar a ser crítica a los 10 días de contagio, se deduce que la población solicita apoyo médico al tener ya un cuadro avanzado con síntomas insoportables. En el contexto mexicano, consideramos que un factor clave que desemboca en esta tendencia es la precariedad económica y laboral que sufre la población.

En México, el $56.2 \%$ de los trabajadores pertenecen al sector informal ${ }^{74}$, aumentando esta cifra en últimas fechas debido a la crisis originada por la pandemia. La necesidad económica ha propiciado que la movilidad y el contacto frecuente se mantengan constantes, generando en lo personal una contradicción entre el riesgo individual de contagio y el beneficio económico familiar. Con el fin de mantener sus ingresos, las personas continúan laborando inclusive después de infectados o teniendo síntomas avanzados, solicitando atención médica hasta el momento en que la enfermedad les impide por completo laborar. Estos aspectos se corroboran de manera estadística teniendo picos de ingresos a hospitales durante los fines de semana, siendo además la mayoría personas con un cuadro agravado y al menos 5 días de sintomatología aguda.

El tercer elemento presente en la población mexicana es una desconfianza amplia al sistema de salud pública, el cual, cabe mencionar, ha sido paulatinamente desmantelado por las políticas neoliberales de los gobiernos en turno durante los últimos 30 años. Este recelo se acrecienta en las zonas urbanas de marginación así como en los pueblos originarios, donde la medicina tradicional y el cuidado familiar se contrapone a la atención médica moderna, occidental. En estos pueblos, y particularmente en Malacachtepec, las distancias geográficas, así como el escepticismo hacia la medicina alópata, han ocasionado que las personas no quieran asistir a los centros especializados o acudan a ellos de manera tardía cuando la atención familiar se ve rebasada.

$74 \quad$ Instituto Nacional de Estadística y Geografía, Encuesta nacional de ocupación y empleo. México, 2019. 
Además de este panorama general, realizamos también un estudio comparativo entre las diferentes alcaldías de la ciudad de México con el fin de conocer el impacto de la pandemia de forma local. Lo que se encontró fue una marcada diferencia entre las zonas urbanas y aquellas rurales y de tradición mesoamericana.

Por un lado, las zonas urbanas proporcionalmente más afectadas fueron las alcaldías Miguel Hidalgo e Iztacalco; la primera por su alto nivel económico y los viajes recurrentes de su población al extranjero, principalmente a EE.UU; la segunda por tener en su demarcación territorial o muy cercanos, tres centros de importante tránsito y desarrollo económico: el Aeropuerto Internacional Benito Juárez, el metro Pantitlán, nodo prominente de transporte público, y la Central de Abasto, lugar de llegada y distribución de todos los alimentos de la ciudad.

En contraste, la zona rural al sur oriente de la ciudad, conformada primordialmente por pueblos originarios nahuas, mantuvo una tasa de contagios mucho mayor a la de las áreas urbanas más afectadas. Malacachtepec particularmente, se ha caracterizado por ser la región con mayor tasa de contagio de la ciudad, estando muy por encima del resto. Este hecho se contrapone fuertemente con la tendencia que muestran otros pueblos originarios de México, quienes por lo común mantienen tasas de contagio por debajo de sus zonas urbanas próximas.

Tener la tasa de contagio más alta de la ciudad de México y al mismo tiempo ser la única alcaldía que mantiene fuertes rasgos culturales mesoamericanos, como el uso de la lengua náhuatl, la agricultura local de milpa, la estructura comunitaria autonómica y un fuerte vínculo emotivo-espiritual con el medio ambiente, podrían hacer de Malacachtepec un punto sensible de análisis por sí sólo; sin embargo, no es esta la única característica que resultó del estudio ni la más importante desde nuestra perspectiva. Si bien los contagios en Malacachtepec son muy altos, su resistencia ante la COVID-19 también lo es, pues mostró que tiene la tasa de letalidad más baja de la ciudad e inclusive una de las más bajas del país.

En México, la letalidad de la COVID-19 a nivel nacional se ha mantenido cercana al 10.2\%. La ciudad de México tiene a la fecha una tasa del $7.69 \%$; sin embargo, existen grandes contrastes entre sus demarcaciones. La alcaldía con mayor 
letalidad es Gustavo A. Madero, con un $10.65 \%$, y la de menor es Milpa Alta, o Malacachtepec con un 3.5\%. Las demás alcaldías oscilan entre estos valores, aunque se pueden agrupar en dos conjuntos bien definidos, uno urbano que muestra letalidades superiores al $6 \%$, y otro rural con importantes zonas de producción agrícola (Milpa Alta, Tláhuac y Xochimilco) cuyas letalidades no sobrepasan el $4.5 \%$.

Para el caso particular de Malacachtepec, las diferentes razones que podemos deducir de una resistencia poblacional tan alta ante la COVID pueden ser de diferentes cortes. Por una parte, las entrevistas realizadas a pobladores y enfermos muestran que 4 de cada 5 pacientes decidieron no acudir a hospitales y recibir los cuidados en sus hogares. Los tratamientos comunes en casa abarcaban tanto medicamentos tradicionales (tés de plantas medicinales locales) como medicinas alópatas así como tanques de oxígeno. Estos elementos han sido, ante los ojos de muchos rehabilitados, lo que ha permitido su recuperación, pero no los únicos. Un complemento inseparable de estos tratamientos es el cuidado parental y el conocimiento que cada familia tiene sobre la mejor manera de tratar enfermedades respiratorias. El saber tradicional de las familias y el apapacho ${ }^{75}$ y cuidado de los seres queridos, promueven una emocionalidad positiva en los pacientes, quienes consideran que enfrentan "con mejor ánimo" la enfermedad y pueden recuperarse mejor.

De esta forma las prácticas comunitarias de atención a enfermos se expresan de manera familiar como parte del paradigma de comunalidad de dichos pueblos, contraponiéndose a la modernidad occidental de atención individual. Este hecho se refleja contundentemente en la percepción de los enfermos recuperados, quienes piensan que de haber ido al hospital regional habrían muerto, siendo su fallecimiento un hecho doloroso, pero no tanto como el incumplimiento de un elemento fundamental e imprescindible para su cultura: los rituales mortuorios comunitarios.

75 El verbo apapachar y el sustantivo apapacho provienen del vocablo náhuatl papachoa, que significa: cubrir, proteger calurosamente, cubrir con cariño, como las gallinas cubren sus huevos. Apapachar significa abrazar o acariciar con el alma. 
Así, morir en el hospital "sin poderse despedir de sus seres queridos" sería la consecuencia de fallecer en la clínica y seguir el protocolo impuesto por el gobierno para estos casos: la cremación sin ninguna ritualidad. El correcto tratamiento del cuerpo del difunto para que cumpla con su destino es un elemento fundamental de las culturas mesaomericanas, y contravenirlo es equivalente a dejar de existir ${ }^{76}$. Este reflejo forma parte del vínculo vida-territorio-cultura que hemos esquematizado en el presente estudio.

Finalmente, otra explicación a tan significativamente baja letalidad puede darse a partir del análisis estadístico. Una interrogante que nos planteamos fue la correlación entre la letalidad y diversos índices socio económicos como la pobreza, la educación, el acceso a la salud, etc. Al calcular dichos coeficientes encontramos que la correlación con la pobreza fue de 0.49 (están poco correlacionados), con el acceso a la salud de 0.73 y con la deficiencia alimentaria de $0.79^{77}$. Así la mayor paridad la encontramos entre letalidad y alimentación, lo que significa que a mejor alimentación menor letalidad y viceversa.

En el marco del seminario virtual "Seguridad alimentaria y COVID-19", realizado en el presente año por el Instituto Nacional de Salud Pública, en México, expertos estimaron la ocurrencia de impactos fuertes del COVID-19 en perjuicio de la seguridad alimentaria en Latinoamérica ${ }^{78}$, lo que puso en cuestión la necesidad de una alimentación saludable para enfrentar tales impactos. Lo cierto es que el análisis mostrado indica que los pueblos nahuas de Malacachtepec, aun en las condiciones de vulnerabilidad a la pueden ser expuestos en el contexto socioeconómico de la ciudad y del país, comprendidas las reducida oportunidades de ocupación laboral que permita una buena remuneración, las carencias del

76 Catalina Rodríguez Lazcano, "Cuidando las ánimas de «nuestros muertos»", en Lourdes Báez Cubero (coord.), Morir para vivir en Mesoamérica, Universidad Veracruzana. México, 2008, p. 92.

77 Se calculó el coeficiente de correlación de Pearson, el cual es un valor entre -1 y 1 . Si dos variables están poco correlacionadas su valor será cercano a 0 , mientras que entre más cercano a 1 o a -1 se encuentre, mayor correlación tendrán.

78 Gobierno de México, <https://coronavirus.gob.mx/2020/07/17/sistemas-de-alimentacionsaludable-contribuiran-a-disminuir-inseguridad-alimentaria-por-covid-19/> ([Última consulta, 14 de octubre de 2020]). 
sistema de salud, y las agresiones al territorio ${ }^{79}$, han mostrado, contrario al diagnóstico de expertos, una fuerte resiliencia a los impactos del COVID-19, lo que podemos advertir, en gran medida se ha debido al ejercicio de la soberanía alimentaria, que aunque imperfecta, el pueblo nahua de Malacachtepec ha ejercido aun, en lo que podríamos observar como un ejemplo de preservación del territorio indígena, interdependiente de la protección ambiental, ecuación que ha mostrado que proporciona las condiciones necesarias para enfrentar un problema tan grave como la epidemia global del COVID-19.

\section{CONCLUSION}

El "territorio" de los pueblos originarios en Latinoamérica, como espacio ontológico multidimensional y hetero-compuesto, debe ser visto desde la lógica de las ontologías políticas de los pueblos originarios, para dotar de una racionalidad consistente a las normas jurídicas cuya interpretación y operación se articula desde espacios de decisión jurídica como la Corte IDH, a partir de la comprensión de los mundos indígenas, de sus particulares apreciaciones de la realidad.

Las fórmulas jurídicas que dan paso al reconocimiento y protección de los derechos de los pueblos originarios en el entorno del SIDH, como en los sistemas jurídicos estatales, deben ser aún acoplados con mayor precisión a esas formas indígenas de mirar sus mundos, si se precisa la efectividad de estas. Las nociones de medioambiente y sus estándares, tanto jurídicos como de derechos humanos, requieren de la adecuación a las realidades epistémicas indígenas que se alcanzan a observar e interpretar, mas o menos fidedignamente desde las visiones occidentales, en la academia, en los espacios de operación jurídica, en el seno de la comunidad estatal.

La perspectiva del territorio y la racionalidad de su defensa frente a los riesgos causados por el estado de manera directa, o indirecta, ya sea por prácticas

79 Además de la tala ilegal que se sufre en los montes de Malacachtepec, los testimonios recabados, provenientes de personas integrantes de la comunidad Santa Ana Tlacotenco, han indicado que algunas de las especies animales del monte son depredadas por perros cuidadores de ganado, la contaminación del suelo con pesticidas para el cultivo del nopal, y la provocación de incendios para favorecer el pastoreo del ganado. 
extractivistas de elementos naturales, o por contingencias sanitarias de gran impacto, muestran formas de integrar el vínculo de estas con la protección del medioambiente, lo que representa inevitablemente la defensa de las condiciones de vida de los pueblos, bajo circunstancias que posiblemente no habían sido consideradas antes, y que la pandemia ha permitido observar.

El caso del pueblo nahua de Malacachtepec Momoxca frente a la epidemia COVID19, es un ejemplo, especial, destacado, virtuoso, de la importancia que tiene el ejercicio de la autodeterminación, condición esencial de la autonomía de los pueblos originarios, a través de la preservación del territorio en el sentido expresado en este estudio, y la defensa de la tierra comunal, para la preservación de un sistema de alimentación sano, de alcance material y simbólico que ha garantizado en términos generales la reproducción de dicho pueblo, aun bajo circunstancias complejas del mundo actual, y que extiende su relevancia cuando esta condición ha permitido a dicho pueblo enfrentar con éxito los impactos de la epidemia.

Como se expresa de manera insistente en algunos foros, casos como el del pueblo nahua momoxca, aportan una enseñanza que los pueblos originarios, con sus ontologías relacionales, comparten con el mundo occidental, y que haríamos bien en aceptar si pretendemos vivir con dignidad en este periodo civilizatorio de crisis de la humanidad.

\section{BIBLIOGRAFÍA}

Apffel-Marglin, Fréderique, “¿Espíritus o recursos naturales? Repensando estas categorías", en UNAY RUNA 9 Revista de Ciencias Sociales, Yachay, Saberese Andino-Amazónicos, Lima, 2018.

Blaser, Mario, "La ontología política de un programa de caza sustentable", en Electronic Journal World Anthropologies Network (WAN), núm. 4, 2009.

Bonfil Batalla, Guillermo, "Implicaciones éticas del sistema de control cultural", en León Olivé (comp.), Ética y diversidad cultural, Fondo de Cultura Económica. Colombia, 1997, p. 198. 
Bonilla, Roberto, "Agricultura y tenencia de la tierra en Milpa Alta. Un lugar de identidad" en la revista Argumentos, núm. 61. México, 2009.

----------, "Urbanización rural y economía agrícola de sobrevivencia en la Delegación Milpa Alta”, en la revista Argumentos, núm. 74. México, 2014.

Campos, Ismael et al., "Hipertensión arterial en adultos mexicanos: prevalencia, diagnóstico y tipos de tratamientos.", en Salud pública de México, vol. 60, núm. 3, 2018.

Centro de Investigación sobre el Coronavirus, Universidad John Hopkins, EE.UU, <https://coronavirus.jhu.edu.> ([Última consulta, 14 de octubre de 2020]).

Instituto Nacional de los Pueblos Indígenas, <https://twitter.com/inpimx/status/1288271852557787137?s=21> ([Última consulta, 12 de octubre de 2020]).

Chun Hal, Byung, Hegel y el poder. Un ensayo sobre la amabilidad, Herder. Barcelona, 2019.

Comité DESC, Observación General 12. El derecho a una alimentación adecuada (artículo 11).

Consejo Nacional de Evaluación de la Política de Desarrollo Social, La pobreza en la población indígena de México, 2008 - 2018, $<$ https://www.coneval.org.mx/Medicion/MP/Documents/Pobreza_Poblacion_indige na_2008-2018.pdf> ([Última consulta, 12 de octubre de 2020]).

Convenio sobre Pueblos Indígenas y Tribales, 1989. (Convenio 169 de la OIT).

Corte IDH. Caso de la Comunidad Indígena Yakye Axa vs. Paraguay. Fondo Reparaciones y Costas, sentencia de 17 de junio de 2005.

Corte IDH. Caso comunidades indígenas miembros de la asociación Lhaka Honhat (nuestra tierra) vs. Argentina. Fondo, Reparaciones y Costas, sentencia de 6 de febrero de 2020.

Corte IDH. Caso de la Comunidad Mayagna (Sumo) Awas Tingni vs. Nicaragua. Fondo, reparaciones y costas, sentencia de 31 de agosto de 2001. 
Corte IDH. Caso pueblos Kaliña y Lokono vs. Surinam. Fondo, reparaciones y costas, sentencia de 25 de noviembre de 2015.

Corte IDH, Caso del pueblo indígena Kichwa de Sarayaku vs. Ecuador. Fondo y Reparaciones, sentencia de del 27 de junio de 2012.

Corte IDH. Caso de la comunidad indígena Xákmok Kásek vs. Paraguay. Fondo, reparaciones y costas, sentencia de 24 de agosto de 2010.

Díaz Polanco, Héctor, Autonomía regional: la libredeterminación de los pueblos indios, Siglo XXI/UNAM. México, 1991.

Escobar, Arturo, Sentipensar con la tierra: nuevas lecturas sobre desarrollo, territorio $y$ diferencia, UNAULA. Medellín, 2015, $<$ http://biblioteca.clacso.edu.ar/Colombia/escposunaula/20170802050253/pdf_460.pdf> ([Última consulta, 03 de octubre de 2020]). -----------, "Territorios de diferencia: la ontología política de los «derechos al territorio»", en Cuadernos de Antropología Social, núm. 41.

Entrevista semiestructurada realizada a María Luisa Hernández, integrante del pueblo nahua de la comunidad Santa Ana Tlacotenco, Malacachtepec, de fecha 8 de octubre de 2020.

Entrevista semiestructurada realizada a Jovany Iglesias López, integrante del pueblo nahua de la comunidad Santa Ana Tlacotenco, Malacachtepec, y jefe de la brigada para cuidar el bosque, de fecha 8 de octubre de 2020.

Fondo Acción Solidaria A.C. (FASOL), Relatoría del II Encuentro de defensoras y defensores del territorio. Ciudad de México, 21-23 de noviembre de 2019 [archivo electrónico].

García Leyva, Jaime, Ña na ka'anyo Nuu Yivi: Lo que pensamos en el mundo, <file:///C:/Users/Cuitlahuac\%20Lina/Downloads/54-109-1-SM.pdf> ([Última consulta, 03 de octubre de 2020]).

Gilly, Adolfo y Roux, Rhina, El tiempo del despojo, Itaca. México, 2015. 
Gobierno de México, <https://coronavirus.gob.mx> ([Última consulta, 14 de octubre de 2020]).

--------------, <https://www.gob.mx/inpi/es/articulos/mujeres-indigenasdatos-estadisticos-en-el-mexico-actual?idiom=es $>$ ([Última consulta, 14 de octubre de 2020]).

<https://www.gob.mx/salud> ([Última consulta, 14 de octubre de 2020]).

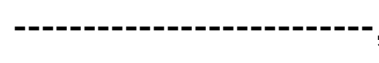
$<$ https://coronavirus.gob.mx/2020/07/17/sistemas-dealimentacion-saludable-contribuiran-a-disminuir-inseguridad-alimentaria-por-covid19/> ([Última consulta, 14 de octubre de 2020]).

Gómezcésar, Iván, "Pueblos invisibles. Los indios en la ciudad de México", en Raquel Gutiérrez y Fabiola Escárzaga (coord.), Movimiento indígena en América Latina: resistencia $y$ proyecto alternativo, vol. II, UAM/UACM/BUAP/UMSA/UPEA/CEAM/Casa Juan Pablos/Gobierno del Distrito Federal, México, 2006.

Hernández, Javier, "El encuentro entre la filosofía andina y el pensar andino" en UNAY RUNA 9 Revista de Ciencias Sociales, Yachay, Saberese AndinoAmazónicos, Lima, 2018.

Hernández, Sandra, "¡Pobladores de Tlacotenco se organizan para defender sus bosques de talamontes!" 23 de junio de 2020, Diario La Jornada, <https://www.jornada.com.mx/ultimas/capital/2020/06/23/pobladores-detlacotenco-se-organizan-para-defender-sus-bosques-de-talamontes-1946.html> ([Última consulta, 4 de octubre de 2020]).

Instituto Nacional de Estadística y Geografía, Encuesta nacional de ocupación y empleo. México, 2019.

Lina, Ivan, "Altepetl, "Una organización territorial comunitaria de Mesoamérica”, en Flores Hernández et al (coord.), Mesoamérica. Una Mirada a través del tiempo, Palabra de Clío. México, 2012, p. 108. 
López Bárcenas, Francisco, Autonomías y derechos indígenas en México, Pez en el árbol. Oaxaca, 2019 (7ª̣ . Edición).

Losada, Teresa, La vigencia de la tradición cultural mesoamericana en Milpa Alta, pueblo antiguo de la ciudad de México, p. 225, <http://www.scielo.org.mx/pdf/rmcps/v47n195/0185-1918-rmcps-47-195-195.pdf> ([Última consulta, 13 de octubre de 2020]).

Organización Mundial de la Salud, Informe mundial sobre la diabetes, 2016.

Relator especial de las Naciones Unidas sobre el derecho a la alimentación. El derecho a la alimentación.

Rodríguez Lazcano, Catalina, "Cuidando las ánimas de nuestros "«muertos»", en Báez Cubero, Lourdes (coord.), Morir para vivir en Mesoamérica, Universidad Veracruzana. México, 2008, p. 92.

Stavenhagen, Rodolfo, La cuestión étnica, El Colegio de México. México, 2001.

Secretaría de Salud, $\quad<$ https://coronavirus.gob.mx/wpcontent/uploads/2020/10/panorama-covid19-poblacion-indigena-240920.pdf> ([Última consulta, 12 de octubre de 2020]).

Thompson, John, Ideología y cultura moderna. Teoría crítica en la era de la comunicación de masas, Universidad Autónoma Metropolitana. México, 2002.

Wacher, Mette, Nahuas de Milpa Alta, CDI. México, 2006. 